\title{
A PROBLEMÁTICA DA ÁGUA NA AGENDA GOVERNAMENTAL DO ESTADO DE SÃo PAULO (1920-1991)
}

\author{
Rodrigo Furtado Eça \\ Universidade de São Paulo (USP) \\ Ana Paula Fracalanza \\ Universidade de São Paulo (USP) \\ Pedro Roberto Jacobi \\ Universidade de São Paulo (USP)
}

\begin{abstract}
A PROBLEMÁTICA DA ÁGUA NA AGENDA GOVERNAMENTAL DO ESTADO DE SÃO PAULO (1920-1991)
Resumo: O trabalho busca identificar os principais elementos econômicos, sociais, políticos e ambientais que estruturaram a gestão dos recursos hídricos ao longo do século XX no Estado de São Paulo, culminando na promulgação da Política Estadual de Recursos Hídricos em 1991. Através da aplicação do Modelo de Múltiplo Fluxos de John Kingdon traça e analisa o processo de inclusão do tema água na agenda governamental. Assim, constata que as soluções apresentadas para enfrentar os problemas de escassez da água, em qualidade e quantidade, dividiam-se entre propostas que alteraram significativamente a definição do uso prioritário das águas estabelecida pelo poder público e propostas que garantiriam a manutenção dos privilégios de setores historicamente beneficiados à custa da degradação dos corpos hídricos. Conclui que, no caso estudado, o modelo de Kingdon iluminou e conectou uma série de elementos que provocaram uma conjuntura favorável à adoção de um novo modelo institucional de gestão da água.

Palavras-chaves: Recursos hídricos, agenda governamental, políticas públicas, modelo de múltiplos fluxos.
\end{abstract}

THE WATER ISSUE IN THE STATE OF SAO PAULO'S GOVERNAMENTAL AGENDA (1920-1991)

Abstract: We sought to identify the economic, social, political and environmental key elements that structured the water management throughout the twentieth century in São Paulo state, Brazil, culminating in the enactment of the Water Resource State Policy in 1991. The application of Multiple Streams Model of John Kingdon allowed us to outline and analyze the introduction process of the water issues in the governmental agenda. It was observed that the solutions presented to face the problems of water scarcity, in terms of quality and quantity, could be divided among proposals that significantly changed the definition of the priority use of the established water by the public authorities and proposals that would ensure the maintenance of the historical privileges of the hydropower sector. In the case studied, the Kingdon's model enlightened and connected several elements that led in direction of a favorable context to the adoption of a new institutional model of water management.

Key words: Water resource, governmental agenda, public policies, multiple streams model. 


\section{INTRODUÇÃO}

A primeira Política Estadual de Recursos Hídricos (PERH) do Brasil foi promulgada em São Paulo no final do ano 1991. As diretrizes e princípios adotados pelo novo modelo de gestão da água refletiam profundas mudanças com relação ao modelo anterior. Segundo Jacobi (2009), nesse momento crucial de inflexão, buscou-se a substituição de uma gestão institucionalmente fragmentada, composta por práticas históricas de planejamento tecnocrático e autoritário, por uma gestão baseada na tríade: integração, descentralização e participação.

$\mathrm{Na}$ Região Metropolitana de São Paulo (RMSP), as questões relacionadas aos aspectos de quantidade e qualidade da água só começaram a ser tratadas como prioridade a partir da década de 1960, quando a degradação e escassez desse recurso natural alcançaram os limites socialmente visíveis, extrapolando a esfera da preocupação puramente técnica, afirma (VICTORINO, 2003). A partir deste momento, o setor energético, amplamente beneficiado pelas políticas de uso da água desde 1920, passou a perder aos poucos a hegemonia construída junto ao poder público. Ao mesmo tempo, os setores ligados ao planejamento e execução de serviços de saneamento básico se fortaleciam.

No intervalo de 30 anos que separa a identificação do problema e a promulgação da $\mathrm{PERH}$, diversos foram os fatores que condicionaram a revisão do modelo de gestão da água em vigência e originariam, consequentemente, a construção de um novo paradigma. Dentre os fatores que contribuíram para as mudanças, pode-se citar: o grau de degradação dos recursos naturais; a mobilização da sociedade civil; o processo de abertura política nacional; e as discussões internacionais sobre desenvolvimento sustentável.

Com base na literatura de Ciência Política, se adotou o Modelo de Múltiplos Fluxos desenvolvido por John Kingdon (1995) para examinar como determinados aspectos das discussões sobre a

Figura 1 - RMSP com destaque para os limites da Bacia Hidrográfica do Alto Tietê e as divisões municipais

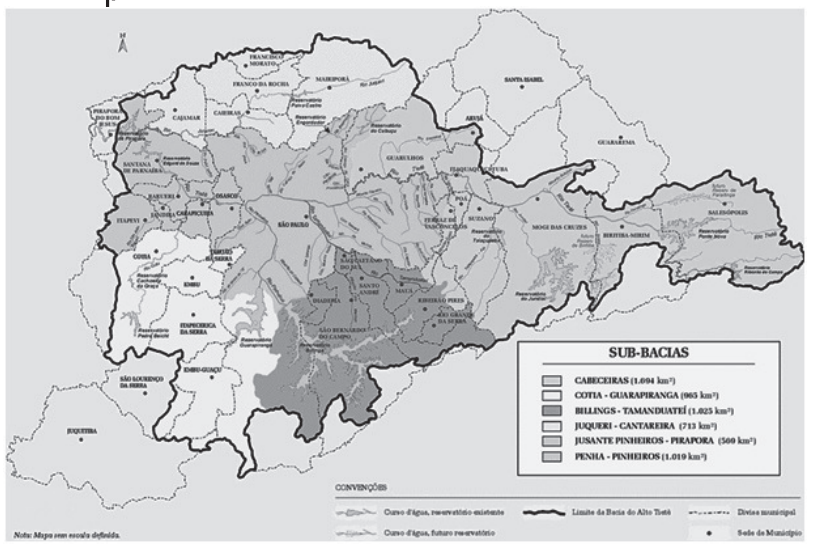

Fonte: Silva e Porto (2003). gestão das águas ganhavam ou perdiam destaque dentro da agenda governamental. De acordo com Faria (2003), Kingdon propõe através de seu modelo responder três questões: Como determinadas temáticas ou problemas atraem a atenção dos tomadores de decisão? Como as alternativas ou soluções são definidas? Como e quando é conduzida a busca por soluções? O presente trabalho tem por objetivo examinar os momentos e elementos que propiciaram a mudança paradigmática ocorrida em 1991 quanto à gestão das águas no Estado de São Paulo à luz do Modelo de Múltiplos Fluxos.

\section{CENÁRIO POLÍTICO-INSTITUCIONAL E INFLEXÕES NA LÓGICA DA GESTÃO DAS ÁGUAS NA RMSP AO LONGO DO SÉCULO XX}

Inicialmente, pretende-se demonstrar como fatores ambientais, sociais, políticos e econômicos moldaram as preferências do poder público quanto à definição do uso prioritário da água em determinados momentos na RMSP, indicando quais foram as implicações para os diversos grupos de interesse e quais foram os impactos sobre a qualidade e disponibilidade dos recursos hídricos.

As questões relacionadas aos múltiplos usos da água na RMSP já se fazem presentes há bastante tempo. Conflitos entre os diferentes usos (como o abastecimento, a produção de energia, a diluição de esgoto e o lazer) foram se intensificando conforme $o$ adensamento urbano intensificava a demanda por água e, ao mesmo tempo, acelerava a degradação das próprias fontes hídricas. Nesse cenário, caracterizado pela degradação e pelo uso intensivo dos recursos naturais, a elaboração de novas propostas para a gestão ambiental se tornaram prementes.

A região de estudo do presente trabalho é a RMSP. Ela foi criada em 1973 e atualmente é composta por 39 municípios, que estão concentrados em uma área intensamente urbanizada de 8.051 $\mathrm{km}^{2}$. Ela é considerada o principal conglomerado urbano do país, sendo que o seu Produto Interno Bruto, no ano de 2011, foi de aproximadamente $\mathrm{R} \$ 707$ bilhões, valor que representa $56 \%$ do PIB estadual. O território da RMSP praticamente coincide com o da Bacia Hidrográfica do Alto Tietê, sendo que apenas $5 \%$ da área da bacia extrapola o território em comum (CAMPOS, 2007). A Bacia do Alto Tietê é definida pela área de drenagem do percurso inicial do rio Tietê e seus afluentes, desde a sua nascente, no município de Salesópolis, até a Barragem de Pirapora. É considerada a bacia com os mais graves problemas hídricos do Estado de São Paulo e uma das mais críticas do mundo. Com relação à água consumida, $45 \%$ é captada em outra bacia hidrográfica. Sob aspectos de qualidade, o nível de criticidade é tão elevado que as soluções convencionais de esgoto sanitário não são mais suficientes para garantir uma melhora na qualidade 
(JACOBI et al, 2009). É nessa região, marcada pela escassez de água em quantidade e qualidade, que vivem aproximadamente 20 milhões de habitantes, praticamente metade da população do Estado de São Paulo ([2012]) (Figura 1).

Rutkowski (1999) sugere que o histórico da gestão das águas doces seja dividido em quatro fases: sanitarista (1890-1934); tecnoburocrática (1934-1963); econômica-financeira (1963-1982); e ambiental (a partir de 1982).

Victorino (2003) identifica dentro da fase sanitarista, no final do século XIX, a primeira clara aparição de questões relacionadas à água na agenda política do Governo Paulista. Nessa época, episódios de déficit de abastecimento eram frequentes, já que o aumento populacional da cidade, que saltou de 31 mil habitantes para 240 mil entre os anos de 1872 e 1900 , não foi acompanhado pelo aumento da oferta de água. Assim, até a década de 1920, a principal preocupação da administração pública era levar água potável às cidades.

Entretanto, São Paulo observa no decorrer do século $X X$ um surto de expansão urbano-industrial, cuja garantia para o desenvolvimento passava necessariamente pelo aumento da disponibilidade energética (BARTH, 2002). Como consequência, as políticas relacionadas à geração de energia elétrica começaram a ser priorizadas, assim como o uso dos recursos hídricos para essa finalidade. Atraída pelas oportunidades econômicas representadas pelas águas de São Paulo, a empresa canadense Light \& Power apresenta ao Governo de São Paulo, no ano de 1920, o Projeto Serra. O projeto originalmente previa que parte das águas do rio Tietê fosse desviada para o reservatório do rio Grande, atualmente conhecido como Billings, e posteriormente utilizadas para produção de energia elétrica na Usina Henry Borden, localizada na Serra do Mar, em Cubatão (VICTORINO, 2003).

O crescente interesse pela construção de novos empreendimentos hidrelétricos gerou um debate sobre o regime jurídico que regia as águas e seu aproveitamento. Em 1934 o Poder Executivo Federal promulgou o Código das Águas, que é considerada, ainda hoje, uma legislação bastante avançada para a gestão dos recursos hídricos. Entretanto, apesar de estabelecer instrumentos e diretrizes para a gestão da água em seus múltiplos usos, apenas os artigos referentes ao aproveitamento hidrelétrico foram regulamentados (BARTH, 2002).

A promulgação do Código das Águas também marca o início da fase tecnoburocrática. Esse período é caracterizado pela implantação de grandiosos projetos para a geração de energia hidroelétrica. O reflexo dessa tendência na RMSP pode ser observado na concessão que a empresa Light \& Power recebe para alterar radicalmente o Projeto Serra, aumentando a quantidade de água desviada do rio Tietê e, consequentemente, a produção de energia em Henry Borden. Para tanto, a represa Billings seria ampliada e as águas do Tietê passariam a ser bombeadas diretamente através do rio Pinheiros, que teria o seu fluxo natural revertido. Victorino (2003) afirma que essa mudança, além de deixar clara a hierarquia das questões na agenda política, simboliza o início do processo de monopolização das águas da RMSP pela Light \& Power. Ao controlar praticamente todo o fluxo de água do Tietê, a empresa canadense inviabilizou qualquer aproveitamento energético no baixo curso do rio, impedindo a entrada de concorrentes, e assim submeteu os interesses dos setores de abastecimento e saneamento às suas operações.

Com o objetivo de gerenciar os recursos hídricos e evitar o conflito entre seus múltiplos usos, é criado, em 1954, o Departamento de Águas e Energia Elétrica (DAEE). Entretanto, o setor de energia elétrica continuou sendo amplamente beneficiado, já que São Paulo, assim como o Brasil, atravessava uma fase de aceleração do crescimento industrial, e uma das principais preocupações do Estado era fornecer eletricidade para o funcionamento do Pólo Industrial de Cubatão. Como consequência, a quantidade de água disponível, que já não era adequada para o consumo, se tornou insuficiente para o abastecimento da população e as condições ambientais da represa Billings se deterioraram rapidamente (BARBOSA, 2003).

A fase econômico-financeira corresponde quase totalmente ao período da ditadura militar, entre 1963 a 1982. Nessa época, a população da capital paulista sofria constantes interrupções no fornecimento de água. Diante da intensificação dos conflitos pelo uso, o governo do Estado encomenda diversos estudos com o objetivo de encontrar uma solução para os problemas de abastecimento e tratamento de esgoto (FRACALANZA; SINISGALLI, 2009; JACOBI, 1993). Segundo Victorino (2003), ao final da década de 1960 é possível perceber uma mudança nos valores que fundamentavam as considerações sobre o planejamento da infraestrutura urbana, a retomada das questões de saneamento básico na agenda de políticas públicas e o início de uma maior correlação de forças entre os blocos de interesse que competiam pelo uso dos recursos hídricos.

Em meio às discussões que ocorreram nos anos seguintes acerca das propostas para solucionar os problemas relacionados ao binômio quantidade e qualidade da água, o destino da represa Billings transformou-se em um centro de disputa que revelava divergências de ordem intersetorial e intergovernamental quanto às propostas elaboradas. De um lado, o setor energético, apoiado pelas indústrias e pelas prefeituras da região da Baixada Santista, era favorável à manutenção da Billings para a produção de energia elétrica. De outro lado, o setor de saneamento básico, apoiado por ambientalistas, engenheiros sanitaristas e as prefeituras dos municípios vizinhos ao reservatório, defendia a requalificação ambiental 
da Billings como manancial de abastecimento e, consequentemente, a interrupção do Projeto Serra (BARBOSA, 2003; VICTORINO, 2003).

Apesar de o tema saneamento ser parte integrante da agenda política do Governo de São Paulo, o foco dado até então privilegiava as operações da Light \& Power. Portanto, as decisões continuaram priorizando os interesses do setor elétrico, da esfera da iniciativa privada, em detrimento dos interesses coletivos representados pelo setor de abastecimento e saneamento (VICTORINO, 2003). No caso do abastecimento, a proposta de purificação e utilização da Billings foi rejeitada. Decidiu-se pela captação de água na bacia hidrográfica do rio Piracicaba, a $70 \mathrm{~km}$ de distância, através do que é atualmente conhecido como Sistema Cantareira, cuja construção teve início em 1966. Campos (2004) enfatiza que essa escolha criou inicialmente um impasse com as autoridades da bacia do Piracicaba, já que a captação prejudicaria os moradores e as atividades econômicas da região. Essa discórdia foi resolvida através da intermediação do Governo Federal, que apoiou a manutenção da lógica prevalecente de geração de energia elétrica.

Noinício da década de 1970, após muito debate sobre o tratamento que seria dado aos esgotos, decidiu-se pela implantação do projeto denominado Solução Integrada. Nessa proposta, a maior parte dos esgotos da Grande São Paulo seria tratada e os efluentes lançados após o local no qual ocorria a reversão do rio Pinheiros. O objetivo secundário dessa proposta seria recuperar a qualidade do reservatório Billings, utilizando parte de suas águas para o abastecimento público, o que implicava na diminuição da produção de energia em Henry Borden. As obras para a construção desse sistema foram iniciadas, mas logo foram interrompidas. No decorrer de um ano, o projeto sofreu profundas modificações e foi renomeado como Sistema de Saneamento da Grande São Paulo (SANEGRAN). O novo plano, elaborado em 1976, definia que os esgotos coletados e tratados seriam devolvidos ao rio Tietê antes do ponto de reversão, assim, o nível de água na Billings e o funcionamento da Usina Henry Borden não seriam alterados (JACOBI, 1993).

Barbosa (2003) afirma que a origem das alterações no projeto se deve a reformas institucionais ocorridas no início da década de 1970 na esfera federal. Nesse momento foi lançado o Plano Nacional de Saneamento (PLANASA), que condicionou a liberação de linhas de créditos aos Estados à criação de uma única companhia estadual, que centralizasse os serviços de saneamento básico e garantisse resultados financeiros compatíveis com o valor dos empréstimos. A partir de uma perspectiva econômica, o projeto SANEGRAN atendia melhor os interesses financeiros, já que satisfazia as exigências do PLANASA e, ao mesmo tempo, beneficiava o bloco empresarial do setor energético. Já da perspectiva ambiental, o plano previa que o lançamento dos efluentes do tratamento do esgoto, que seria em nível secundário, no Tietê, percorrendo a área urbanizada, causaria a deterioração do ambiente urbano e a inutilização das águas para o abastecimento e lazer (BARBOSA, 2003; VICTORINO, 2003).

A decisão favorável ao projeto SANEGRAN abriu um debate intenso que trazia à tona a dissociação entre investimentos em saneamento e seu impacto no planejamento urbano territorial e ambiental e provocou diversas mobilizações contra sua implementação (JACOBI, 1993) Os primeiros sinais e tendências de mudança quanto ao uso setorial das águas em São Paulo começaram a despontar na segunda metade da década de 1970. Três fatores convergiram e contribuíram para o processo de mudança institucional que a gestão dos recursos hídricos iria atravessar nos anos seguintes

No cenário internacional, repercutiam os informes do Clube de Roma e as declarações da $1^{\text {a }}$ Conferência Mundial das Nações Unidas sobre Meio Ambiente, na qual despontavam pela primeira vez as contradições emergentes da falta de integração entre as políticas ambientais e as de desenvolvimento econômico. O Brasil sofria uma forte pressão nacional e internacional, dos movimentos ambientalistas e de alguns organismos financiadores quanto ao nível crescente de degradação do seu patrimônio natural.

No Estado de São Paulo, atores sociais surgem na arena pública de debate, que antes era monopolizada pelo setor energético e de saneamento básico, tratado essencialmente sob aspectos técnicos. Duas mobilizações sociais são emblemáticas e exemplificam essa mudança. A primeira, denominada Movimento de Defesa da Billings, reuniu a população do grande $A B C$ contra o Projeto SANEGRAN e a reversão do rio Pinheiros. A demanda pela preservação do meio ambiente e da saúde publica culminaram em uma ação popular, proposta em 1977. A segunda mobilização se desdobrou no município de Piracicaba, durante o mesmo período. Entidades profissionais e da sociedade civil, preocupadas com o comprometimento das águas do rio Piracicaba, em qualidade e quantidade, que se agravou após a operação do Sistema Cantareira, iniciaram uma campanha em prol da sua recuperação. As demandas e sugestões elaboradas ao longo da campanha foram reunidas sob a forma de uma Carta de Reivindicações, entregue ao Governo de São Paulo em 1985. Algumas dessas reivindicações, como a criação de um organismo intergovernamental de gestão, contribuíram significativamente para as modificações institucionais no modelo de gestão de água que seriam realizadas (VICTORINO, 2003; BARBI; CASTELLANO, 2006; AGÊNCIA NACIONAL DAS ÁGUAS, 2007; JACOBI, 1993).

Por fim, a conclusão de outras usinas hidrelétricas, como a Itaipu Binacional, no final da 
década de 1970, gerou um excedente na capacidade de produção de energia, o que diminuiu a importância da usina Henry Borden e, consequentemente, a influência exercida pela empresa Light \& Power na definição de políticas públicas (VICTORINO, 2003; BARBOSA, 2004).

Para Rutkowski, a fase ambiental de gestão das águas inicia-se em 1982. Neste momento, marcado pelo início da redemocratização, explicitase uma crescente demanda por maior publicização do Estado; com a repercussão do debate internacional sobre o desenvolvimento sustentável e a escassez hídrica, novos arranjos institucionais para a gestão dos recursos hídricos começam a ser elaborados. Nesse sentido se inicia um processo de discussão sobre a necessidade de remodelação do sistema de gestão das águas do estado de São Paulo.

\section{CONSTRUÇÃO DE AGENDA GOVERNAMENTAL: apresentando o modelo de} múltiplos fluxos

Na ciência política, segundo Faria (2003), as análise de políticas públicas sempre privilegiaram os momentos decisórios, atribuindo pouca importância ao papel das ideias e do conhecimento, elementos que são cruciais para entender o processo de formação da agenda política. Nesse campo de pesquisa, o modelo de Múltiplos Fluxos (Multiple Streams) desenvolvido por John Kingdon (1995) é um dos mais indicados para se analisar a formação da agenda governamental em ambientes marcados pela instabilidade e ambiguidade de objetivos e preferências (FARIA, 2003; SOUZA, 2006).

Segundo o modelo de Múltiplos Fluxos, a proeminência de uma questão na agenda de decisão é determinada pela convergência de três correntes - reconhecimento do problema, formulação de soluções e processo político. O reconhecimento do problema por parte dos tomadores de decisões governamentais pode ocorrer, principalmente, através de quatro meios - experiência pessoal dos envolvidos, análise de indicadores, feedback das ações governamentais ou como consequência de uma crise ou evento dramático.

Quanto à formulação de soluções, o modelo assume que especialistas da comunidade de políticas públicas desenvolvem e apresentam diferentes propostas, cuja seleção ocorrerá através de critérios de viabilidade técnica, financeira e aceitação política. As propostas selecionadas poderão ser utilizadas na sua concepção original ou serem combinadas umas às outras, originando novas propostas. Kingdon enfatiza que as soluções não se relacionam, necessariamente, ao conhecimento de problemas específicos.

Quanto ao processo político, essa corrente reúne três elementos que podem proporcionar uma conjuntura política favorável à entrada de uma questão na agenda - sentimento nacional, forças políticas organizadas e mudanças no governo. O primeiro elemento é caracterizado pela comoção nacional, ou seja, o momento no qual um número significativo de pessoas pensa e valoriza segundo parâmetros comuns a mesma questão. Já as forças políticas organizadas exercem basicamente o papel de grupos de pressão, dificultando ou facilitando a mudança do status quo. O último elemento se relaciona com um amplo espectro de eventos internos ao governo, como, por exemplo, na mudança de pessoal nos cargos-chaves, na composição do Congresso Nacional ou no arcabouço institucional, que podem desencadear processos que excluam ou incluam questões na agenda.

Essas três correntes se desenvolvem segundo suas próprias dinâmicas e regras, mas apesar de independentes, elas são permeáveis entre si. Entretanto, sob determinadas circunstâncias, normalmente associadas ao surgimento de um contexto político favorável ou ao reconhecimento de um problema, abrese uma "janela de oportunidade de políticas". Nesse momento, surge uma demanda política por soluções e os especialistas têm a oportunidade de apresentar suas ideias e propostas. Quando as três correntes estão conectadas, a probabilidade de a questão entrar na agenda governamental aumenta consideravelmente.

A conexão entre as correntes dificilmente ocorre de forma espontânea, pois depende da atuação dos "empreendedores de políticas", caracterizados como pessoas dispostas a investir tempo, energia, reputação e, algumas vezes, recursos financeiros. Eles podem ser encontrados dentro do governo, nos partidos políticos, na academia ou nos lobbies. Os incentivos que os motivam são os mais variados, como, por exemplo, ganhos materiais, reconhecimento ou realização ideológica. Geralmente são pessoas especialistas na questão, com aptidão e disposição para a negociação, e que possuem conexões políticas.

No momento em que uma janela se abre, os empreendedores se esforçam para obter algum tipo de vantagem, pois sabem que ela não permanecerá aberta por muito tempo. O fechamento de uma janela ocorre quando uma das correntes se desarticula face às demais, condição que pode perdurar por um longo período de tempo. Pode-se deduzir que a construção de uma política pública, segundo Kingdon, não se origina de um processo sequencial e ordenado, mas de uma lógica sistêmica e contingente, como demonstrado pelo processo de convergência entre problema, solução e aceitação política (GOMIDE, 2008). A seguir se examina o processo de definição da agenda governamental do Estado de São Paulo, principalmente a partir da segunda metade do século $X X$, em torno dos recursos hídricos, identificando os principais fatores e elementos que permearam e influenciaram esse processo. 


\section{INTRODUÇÃO DAS QUESTÕES DOS RECURSOS HÍDRICOS NA AGENDA GOVERNAMENTAL DO ESTADO DE SÃO PAULO}

Nesta seção se descreve e reflete sobre o processo que culminou na promulgação da Lei $n^{\circ}$ 7.663, de 30 de dezembro de 1991, que estabeleceu a Política Estadual de Recursos Hídricos e criou o Sistema Integrado de Gerenciamento dos Recursos Hídricos. Para tal fim, optou-se em caracterizar alguns dos elementos de análise descritos no Modelo de Múltiplos Fluxos - correntes, janela de oportunidade e empreendedores de políticas - na sequência cronológica em que foram observados ao longo do processo de construção de agenda governamental quanto às questões envolvendo água no Estado de São Paulo.

A abertura da janela de oportunidades ocorreu de acordo com o proposto pelo Modelo de Múltiplos Fluxos, na medida em que a definição dos problemas e soluções foi sendo alterada ao longo do tempo. Segundo Kingdon (1995), a abertura da janela é determinada principalmente pela corrente do processo político ou dos problemas, sendo que a corrente de soluções não influenciaria diretamente nesse processo. A partir do momento em que o Estado reconheceu a condição crítica na qual se encontravam os recursos hídricos e sinalizou a importância dessa questão, os atores políticos interessados apresentaram as suas interpretações sobre a natureza dos problemas e suas propostas para solucioná-los, ao mesmo tempo em que mobilizavam seus recursos de poder para defender suas visões e interesses.

A definição quanto ao uso prioritário das águas da RMSP constituía-se como o cerne do conflito entre duas interpretações divergentes sobre a natureza do problema. A primeira interpretação almejava alterar a definição vigente do uso prioritário da água e garantir, consequentemente, a recuperação da qualidade ambiental dos corpos hídricos. As propostas de soluções que mais convergiam com essa interpretação do problema previam a recuperação da qualidade das águas da represa Billings, no caso do abastecimento, e o afastamento dos efluentes, provenientes do tratamento do esgoto, da região mais urbanizada e povoada da bacia do Alto Tietê ${ }^{1}$.

Já na interpretação alternativa, o problema era reconhecido como uma questão de abastecimento e tratamento de esgoto. Nesse caso, as questões relacionadas à alteração das políticas que historicamente priorizavam o uso das águas da RMSP para a geração de energia elétrica eram desconsideradas. O problema, de acordo com a segunda interpretação, era garantir o fornecimento dos serviços básicos de saneamento na quantidade demandada. A busca por soluções externas e que não interferissem no cenário estabelecido de uso e gestão das águas, marcado pela escassez e degradação, estavam em primeiro plano. As propostas para resolver os problemas sugeriam captar água para abastecimento na bacia do rio Piracicaba, cuja disponibilidade hídrica já apresentava déficits na época de estiagem, e lançar os efluentes do tratamento do esgoto dentro da área urbanizada, permitindo que fosse utilizado para a geração de energia elétrica. Nesse cenário, a concentração da carga poluidora impediria o processo de autodepuração e comprometeria parte da bacia do Alto Tietê para o abastecimento e lazer.

Como o processo de crescimento econômico no período, simbolizado pela expansão industrial, ocupava lugar central na agenda governamental, juntamente com a ampliação da capacidade de produção de energia elétrica, não existia um ambiente político favorável para promover a redefinição dos usos prioritários da água, que também enfrentava a resistência do setor elétrico, que não queria perder o tratamento especial recebido. Portanto, as propostas que resolviam parcialmente os problemas de abastecimento e tratamento de esgoto, mas não comprometiam a produção de energia elétrica, foram escolhidas. A construção do Sistema Cantareira começou em 1967 e a implantação do Projeto SANEGRAN foi iniciada em meados dos anos 1970.

Ocorre nesse momento a conexão entre a corrente do processo político, do problema e da solução. Contudo, a questão que entrou na agenda tratava, na verdade, dos sintomas, e não dos problemas. Era, portanto, uma questão de tempo até que a condição dos recursos hídricos se tornasse crítica novamente. Logo, a primeira definição do problema, assim como as respectivas soluções, continuaram sendo enfatizadas por seus empreendedores, que agora precisavam esperar pelo surgimento de uma nova janela de oportunidades.

A janela seria reaberta no início do governo de André Franco Montoro, em 1983. Como estabelece o Modelo de Múltiplos Fluxos, é a corrente do processo político que geralmente inicia o processo de conexão com as demais. No caso estudado, o processo de redemocratização e a eleição de Franco Montoro promoviam uma conjuntura política favorável à entrada de questões relacionadas à reestruturação do modelo de gestão dos recursos hídricos na agenda governamental, já que os três elementos que compõem a corrente do processo político se faziam presentes.

O primeiro elemento trata das mudanças internas ao governo, que possuem a capacidade de excluir ou incluir questões na agenda de acordo, por exemplo, com opções ideológicas. Em 1982, ocorreram as primeiras eleições diretas para governadores e prefeitos desde 1965. O governo de São Paulo é assumido por Franco Montoro, que estabeleceu como prioridade a implementação de um modelo institucional mais democrático, descentralizado e participativo (LIMA, 2009). 
Quanto ao segundo elemento, o sentimento público, definido por Caldas (2007) como a formação de uma atmosfera favorável à germinação de uma ideia, pode se observar que duas grandes mobilizações da sociedade civil utilizaram como bandeira a conservação ambiental e a melhoria nas condições de qualidade de vida para exigir a recuperação dos corpos d'água e a reestruturação do sistema de gestão. Outra mobilização de apoio à despoluição dos rios ocorreu em 1990, quando uma estação de rádio ${ }^{2}$, por ocasião do aparecimento de um jacaré nas águas poluídas do Tietê, iniciou uma série de reportagens sobre a degradação de suas águas, cuja repercussão atingiu outros órgãos de imprensa e sensibilizou segmentos da população sintonizados com a problemática da degradação ambiental. Em seis meses foram coletadas 1,2 milhões de assinaturas que solicitavam providências (FRACALANZA, 2002). Todos esses eventos tornavam visível para o governo do Estado os anseios da população pela recuperação ambiental dos seus rios.

O terceiro elemento aborda os grupos de pressão favoráveis e contrários às modificações institucionais na gestão da água. Como anteriormente apresentado, o setor energético, principal prejudicado com relação às mudanças planejadas, perde parte de seu poder de influência ao longo dos anos 80 . Esse fato, somado à visibilidade que a questão dos recursos hídricos alcança na sociedade, provocou a diminuição da oposição por parte de outros setores do governo ou grupos de pressão quanto à presença dessas questões na agenda.

A partir desse momento, a primeira definição do problema, baseada na redefinição do uso prioritário da água, no estabelecimento de uma política que promovesse os múltiplos usos e em mecanismos que tornassem a exploração mais racional, encontrava apoio dentro das esferas governamentais. Para completar o cenário, o enfraquecimento dos grupos de interesses ligados ao setor elétrico, por um lado, e a mobilização da sociedade civil em prol da recuperação dos rios, por outro, retirou de cena um opositor e trouxe um aliado às mudanças.

Dentre os mecanismos de reconhecimento de problemas descrito por Kingdon, dois se sobressaiam nesse caso. Os indicadores, com certeza, acusavam a situação critica de degradação, refletida na poluição das águas do Tietê e da Billings, e a escassez, refletida na captação de $54 \%$ da água consumida em outra bacia hidrográfica. Com relação ao mecanismo de feedback, Carlos Estevam Martins (2001) afirma que a rivalidade existente entre os setores da administração responsáveis pelas questões de crescimento econômico e conservação ambiental sempre foi motivo de preocupação. Isso remete ao conflito intersetorial testemunhado entre energia elétrica e saneamento básico, e pode ser considerado como um feedback quanto aos resultados negativos originados pela atuação fragmentada e conflituosa entre as diversas agências e secretarias do Estado.

Por fim, quanto à corrente das soluções, pode-se traçar três importantes fontes de propostas. Segundo Martins (2001), durante o Governo de Franco Montoro (1983-1987), dois grupos de trabalho, um baseado no DAEE e outro na FUNDAP, ficaram responsáveis por desenvolver o modelo de gestão descentralizado, participativo e integrado das águas $^{3}$. Outro grupo de especialistas que debatia questões semelhantes no período era a Associação Brasileira de Recursos Hídricos (ABRH). Grande parte das sugestões presentes na Carta de Salvador (1987) e Foz do Iguaçu (1989) foram adotadas pela lei paulista de recursos hídricos, como a descentralização do processo decisório, a gestão por bacia hidrográfica e a adoção de instrumentos de cobrança pelo uso da água (BARTH, 2003).

Os especialistas da ABRH também defendiam a participação pública, mas com a ressalva de que ocorresse apenas através da informação e consulta. Já os dois grupos de trabalho do governo de São Paulo, cientes de que o discurso técnico havia sido usado no passado para legitimar a ausência de debate publico e isolar os lócus de poder decisório, beneficiando determinados grupos econômicos e burocráticos; defendiam a ampliação das relações entre Estado-sociedade e a politização da gestão dos recursos hídricos (MARTINS, 2001; BARTH, 2003)

Exemplos de gestão e propostas de solução também provinham do município de Piracicaba. A Carta de Reivindicações entregue ao governo de São Paulo em 1985 foi fruto direto da mobilização denominada "Campanha Ano 2000 - Redenção Ecológica da Bacia do rio Piracicaba", liderada pelo Conselho Coordenador das Entidades Civis e pela Associação dos Engenheiros e Arquitetos de Piracicaba, que tinha como meta promover a reestruturação ética e técnico-financeira da bacia hidrográfica. Os princípios e demandas dessa campanha foram fundamentais para a criação do Conselho Estadual de Recursos Hídricos (1987) e do Consórcio Intermunicipal das Bacias dos Rios Piracicaba e Capivari (1989), cujo objetivo era complementar a atuação das entidades públicas responsáveis pela execução de políticas de saneamento e conservação ambiental (BARBI; CASTELLANO, 2006; CASTELLANO, 2007).

Aparentemente, a criação, a alteração, o veto e a reformulação de ideias e soluções para resolver o problema da gestão da água orbitavam em torno das associações e autoridades citadas acima. Em geral, as soluções apresentadas e defendidas guardavam certa sintonia, destoando apenas quanto ao papel da sociedade civil no processo de decisão. Entretanto, esses eram os atores visíveis ou que afetavam formalmente o processo. Martins (2001) afirma que durante o processo de criação do SIGRH, propostas análogas para outras áreas da 
administração pública também foram debatidas e colocadas em prática, como as Regiões de Governo e o Orçamento Regionalizado, mas não foram bem sucedidas. Segundo Martins, os principais opositores a essas ideias eram os secretários de estado, que temiam perder poder quanto à alocação dos recursos setoriais, os deputados, que temiam perder sua importância como intermediários entre os prefeitos e o governador, os prefeitos dos grandes municípios, que temiam perder o acesso privilegiado ao governador, os funcionários dos órgãos setoriais, que temiam perder o abrigo das rotinas burocráticas e, por fim, os interesses econômicos e políticos, que perderiam a oportunidade de "parasitar" verbas da administração pública. Esses participantes poderiam ser considerados como atores invisíveis do processo, cuja atuação, segundo Kingdon, afetaria principalmente as alternativas, enquanto os participantes visíveis e formalizados afetariam a agenda.

Os principais pontos que contribuíram para a difusão das ideias e dos valores que influenciaram o processo de definição da agenda governamental a respeito dos recursos hídricos indicam que o início do governo Montoro foi marcado por um processo de transição democrática, que buscava se distanciar das características do período anterior, o regime militar. No mesmo período, embora a escassez e a poluição das águas já representassem um antigo problema para a RMSP, a redefinição do problema aumentou a mobilização da opinião pública e a demanda por soluções. Tais questões já eram debatidas pela Associação Brasileira de Recursos Hídricos, sob o prisma dos aspectos técnicos, e pelas Entidades Civis e Profissionais de Piracicaba, com maior ênfase nos aspectos políticos. As propostas e sugestões apresentadas por esses grupos influenciaram e serviram de subsídio para os integrantes dos dois grupos de trabalho responsáveis pela construção do Sistema Integrado de Gerenciamento de Recursos Hídricos do Estado de São Paulo, situados no DAEE e na FUNDAP. Portanto, os integrantes desses dois grupos podem ser considerados os empreendedores políticos nessa ocasião, que aproveitando a conjuntura política favorável, realizaram a conexão entre a corrente do problema e das soluções, criando desta forma as condições necessárias para promover uma mudança considerada paradigmática no sistema de gestão.

O marco deste novo sistema foi a aprovação da Lei Estadual n 7.663, em 1991, que institui a Política Estadual de Recursos Hídricos. Como objetivo principal, a nova lei estipulava diretrizes e estabelecia instrumentos que proporcionariam os múltiplos usos da água e garantiriam a sua proteção, em qualidade e quantidade. Três princípios fundamentavam como deveria ocorrer a gestão das águas de acordo com a nova legislação: 1) ser descentralizada, adotando a bacia hidrográfica como unidade ideal de gestão, o que resultou, em 1993, na divisão do Estado de São Paulo em 22 Unidades de Gerenciamento de
Recursos Hídricos; 2) ser participativa, garantindo espaço para que a sociedade civil possa, de fato, tomar parte dos processos de decisão; 3) ser integrada, enfatizando a necessidade da atuação conjunta entre diversos órgãos da administração Estadual e Municipal. Nesse sentindo, a fórmula proposta para o funcionamento do SIGRH foram os Comitês de Bacias Hidrográficas, órgãos colegiados tripartites, consultivos e deliberativos.

\section{CONCLUSÃO}

O objetivo deste trabalho foi examinar, à luz do Modelo de Múltiplos Fluxos, alguns dos momentos e elementos que promoveram a entrada de questões relacionadas aos recursos hídricos na agenda governamental do Estado de São Paulo, processo este que abriu caminho para a reformulação do sistema de gestão das águas no Brasil. As informações apresentadas resgataram o processo de construção da agenda e demonstraram a importância da corrente denominada processo político.

Como se observou, a relevância política do setor energético provocou o adiamento das propostas que alterariam significativamente as diretrizes para a gestão das águas. Desta forma, as soluções implementadas, em um primeiro momento, incidiam sobre os efeitos que o modelo de gestão vigente, fortemente influenciado pela conjuntura econômica-política do período, infringia sobre os corpos hídricos da RMSP. Logo, a baixa oferta de água em quantidade e qualidade que ameaçavam a população e as atividades da região entre as décadas de 1970 e 1980 constituíam-se como sintomas das decisões políticas quanto à priorização dos usos deste recurso. Somente uma década depois, em 1990, com as transformações que se desdobravam nos planos político e econômico, a janela de oportunidade foi reaberta e novas propostas para solucionar os problemas foram apresentadas.

A grande inovação que surgiu com a promulgação da Política Estadual de Recursos Hídricos foi a abertura do processo de decisão e gestão à participação de diversos segmentos da sociedade civil através da criação dos Comitês de Bacias Hidrográficas, que são órgãos consultivos e deliberativos com competência para promover a gestão participativa dos recursos hídricos dentro dos limites das bacias hidrográficas. A garantia da participação social aumenta a legitimidade das decisões tomadas dentro destes fóruns e aumenta o controle social e a transparência dos processos de formulação, avaliação e implementação de políticas públicas. A lógica do colegiado, baseada em negociações sociotécnicas, e a sua dinâmica, que torna a interação dos atores envolvidos mais transparente, deveriam desestimular atitudes de abuso de poder e neutralizar práticas predatórias estimuladas por interesses econômicos e políticos. 
Entretanto, enquanto alguns riscos realmente são atenuados, como a utilização dos comitês por interesses específicos, o risco de manipulação e ingerências por parte do Poder Executivo ainda é uma ameaça.

Atualmente, o conjunto de expectativas positivas quanto à atuação dos Conselhos Gestores Participativos, como os Comitês de Bacias, e à concretização de seus princípios passa por um período de descrédito devido às dificuldades encontradas. A simples criação de novas instituições não garante maior pluralidade e equilíbrio na participação da sociedade civil e não é suficiente para modificar a lógica tradicional do poder. Parte da concretização dos princípios democráticos que fundamentam as novas arenas de gestão e decisão é prejudicada pela capacidade desigual quanto à posse e mobilização dos recursos de poder por parte dos atores políticos. Apesar da importância do debate quanto à qualidade, igualdade e amplitude da participação, as reformas quanto à escala de atuação das instituições e da participação da sociedade civil não garantem a concretização dos princípios e objetivos que legitimam a implantação das arenas participativas.

Enquanto a reformulação e a implantação de um novo modelo de gestão de recursos hídricos encontraram no campo político suporte euma recepção positiva, pelos motivos já apresentados, modificações que trariam maior efetividade e operacionalidade à atuação dos Comitês e, consequentemente, ao SIGRH já não desfrutam atualmente das mesmas oportunidades, ou seja, a janela de oportunidade que possibilitaria a intervenção na realidade políticoinstitucional que estrutura esse sistema de gestão encontra-se fechada. Como aponta Kingdon, a janela só é aberta quando as três correntes se conectam, sendo que a corrente do processo político geralmente se destaca por iniciar o processo que irá provocar a conexão. Atualmente, apesar da multiplicação das organizações não governamentais que atuam no campo socioambiental, não se observa uma mobilização tão forte e pública por parte da sociedade civil, como a que ocorreu no final da década de 1980. Por outro lado, o compromisso inicial assumido pelas autoridades governamentais em descentralizar e democratizar o processo de gestão das águas pode ter perdido o impulso ao longo dos anos, condição que enfraqueceu a atuação dos Comitês de Bacias e contribuiu para manter a janela de oportunidades fechada.

Para finalizar, a análise do histórico quanto à utilização das águas na RMSP em face da perspectiva teórica fornecida por Kingdon possibilitou a identificação de alguns fatores que influenciaram o processo de formulação das políticas públicas, determinando o avanço ou recuo da incorporação de novas propostas de solução. Uma análise mais minuciosa e aprofundada desses fatores poderá iluminar os obstáculos que atualmente impedem que o Sistema de Gestão Integrada dos Recursos Hídricos opere de forma mais eficiente, cumprindo com o conjunto de expectativas positivas que fundamentam a sua existência e justificaram a sua criação.

\section{REFERÊNCIAS}

AGÊNCIA NACIONAL DAS ÁGUAS. A Implementação da cobrança pelo uso de recursos hídricos e Agência de Água das Bacias dos Rios Piracicaba, Capivari e Jundiaí. Brasília, Df, 2007.

BARBI, F; CASTELLANO, M. Avanços na gestão compartilhada dos recursos hídricos nas bacias dos Rios Piracicaba, Capivari e Jundiaí. São Paulo em Perspectiva, São Paulo, v. 20, n. 2. 2006.

BARBOSA, H. B. O Desafio da Gestão Integrada: Recursos Hídricos na Grande São Paulo. 2003. 83 f. Dissertação (Mestrado em Administração de Empresas) - Curso de Pós-graduação da Escola de Administração de Empresas de São Paulo, Fundação Getúlio Vargas, São Paulo, 2003.

BARTH. F.T. Aspectos institucionais do gerenciamento de recursos hídricos. In: Águas doces no Brasil: capital ecológico, uso e conservação. São Paulo: Escrituras, 2002.

CALDAS, E. L. Formação de agendas governamentais locais: o caso dos consórcios municipais. 2007. 227 f. Tese (Doutorado em Ciência Política) - Programa de Pós-Graduação em Ciência Política, Universidade de São Paulo, São Paulo. 2007.

CAMPOS, V. N. O. Novos Arranjos, velhos problemas. In: ENCONTRO NACIONAL DA ANPPAS, 2., 2004. Anais... Indaiatuba, 2004.

O comitê de bacia hidrográfica do Alto Tietê e o Consejo de Cuenca del Valle de México: potencialidades e limites da gestão participativa da água. 1980-2005. 2007. Tese (Doutorado em) - Programa de Pós-graduação em Integração da América Latina, Universidade de São Paulo, São Paulo. 2007.

CASTELLANO, M. Relações entre poder público e sociedade na gestão dos recursos hídricos: o caso do Consórcio Intermunicipal das Bacias Hidrográficas dos Rios Piracicaba, Capivari e Jundiai. 2007. 265 f. Tese (Doutorado em Ciência Ambiental) Universidade de São Paulo, São Paulo, 2007.

FARIA, C. A. P. Idéias, conhecimento e políticas públicas: um inventário sucinto das principais vertentes analíticas recentes. Revista Brasileira de Ciências Sociais, São Paulo, v. 18, n. 51. 2003. 
FRACALANZA, A. P. Conflitos na apropriação da água na Região Metropolitana de São Paulo. 2002. 217 f. Tese (Doutorado em Geografia) Faculdade de Ciências e Tecnologia, Universidade Estadual Paulista, Presidente Prudente, SP, 2002.

; SINISGALLI, P. A. Conflitos de uso da água do Reservatório Billings. In: JACOBI, P. R. (Org.). Atores e processos na governança da água no Estado de São Paulo. São Paulo: Annablume, 2009.

GOMIDE. A. A. Agenda governamental e formulação de políticas públicas: o projeto de lei de diretrizes da política nacional de mobilidade urbana. Texto para discussão, Brasília, DF, n. 1334, 2008.

JACOBI, P. R. et al. Governança das águas da Região Metropolitana de São Paulo (Brasil): o caso do Comitê da Bacia Hidrográfica do Alto Tietê. In: JACOBI, P. R.; SINISGALLI, P. A. (Org.). Dimensões político institucionais da governança da água na América Latina e Europa. São Paulo: Annablume, 2009.

Governança da Água no Brasil. In: RIBEIRO, W. C. (Org.). Governança da água no Brasil: uma visão interdisciplinar. São Paulo: Annablume, 2009

Movimentos sociais e políticas públicas. São Paulo: Cortez, 1993.

KINGDON, J. W. Agendas, alternatives and public policies. New York: Longman, 1995.

LIMA. J. C. Franco Montoro. Brasília, DF, 2009. (Perfis Parlamentares, n. 54).

MARTINS, C. E. Gestão da água em São Paulo: o feito e o a fazer. In: Congresso Estadual de Comitês de Bacias Hidrográficas, 1., 2001, São Pedro, SP. Anais... São Pedro, SP: SMA 2001.

RUTKOWSKI, E. Bacia hidrográfica e bacia ambiental. São Paulo: SABESP, 1999.

SILVA, R. T.; PORTO, M. F. A. Gestão urbana e gestão das águas: caminhos da integração. Estudos Avançados, São Paulo, v. 17, n. 42, 2003.

SOUZA, C. Políticas públicas: uma revisão da literatura. Sociologias, Porto Alegre, n. 16, p. 20-45, 2006.

VICTORINO, V. I. P. Monopólio, conflito e participação na gestão dos recursos hídricos. Ambiente \& Sociedade, São Paulo, v. 6, n. 2, 2003.

SÃO PAULO. Secretaria de Planejamento e Desenvolvimento Regional. Fundação Sistema Estadual de Análise de Dados. Perfil da Região Metropolitana de São Paulo. [2012]. Disponível em:<http://www.seade.gov.br/produtos/perfil_ regional/index.php>. Acesso em: 20 fev. 2013.
Notas

Acreditava-se que após a realização de tratamento em nível secundário do esgoto, o próprio rio, através do processo de autodepuração, teria capacidade para recuperar a qualidade natural de suas águas.

2 Rádio Eldorado pertencente ao grupo Estado de São Paulo.

3 O grupo baseado no DAEE era composto por Valdemar Casadei, João Lotufo, Rui Brasil, Luis Fernando Carne Seca e Flavio Terra Barth; já o grupo da FUNDAP era formado por Hadjimu Miyashita, Sandra Inês Baraglio Granja, Ana Lúcia Magyar e Eduardo Yassuda.

\section{Rodrigo Furtado Eça}

Gestor Ambinetal

Mestrando pelo Programa de Pós-Graduação em Ciência Ambiental (PROCAM/USP)

Gestor Ambiental pela Escola de Artes Ciências e Humanidades $(\mathrm{EACH})$ da Universidade de São Paulo (USP)

E-mail: rodrigofurtado@usp.br

\section{Ana Paula Fracalanza}

Socióloga e economista

Doutora em Geografia pela Universidade Estadual Paulista

"Júlio de Mesquita Filho" (UNESP)

Professora da Escola de Artes, Ciências e Humanidades, do Programa de Pós Graduação em Mudança Social e Participação Política (PROMUSPP) e do Programa de Pós Graduação em Ciência Ambiental (PROCAM) da Universidade de São Paulo (USP)

E-mail: fracalan@usp.br

Pedro Roberto Jacobi

Cientista social e economista

Doutor em Sociologia pela Universidade de São Paulo (USP)

Professor Titular da Faculdade de Educação e do Programa de Pós-Graduação em Ciência Ambiental (PROCAM) da Universidade de São Paulo (USP)

E-mail: prjacobi@usp.br

Universidade de São Paulo (USP)

Cidade Universitária, São Paulo - SP

CEP: 05508-900 